\title{
Adaptation of urban roads to changing of transport demand
}

\author{
Sergey Ertman ${ }^{1 \mathrm{a}}$, Juliya Ertman $^{1}$, and Dmitriy Zakharov ${ }^{1}$ \\ ${ }^{1}$ Automobile Transport Operation Department, Transport Institute, Tyumen Industrial University, \\ 625000, Tyumen, Russia
}

\begin{abstract}
To realize the paradigm of the "Sustainable city" it is necessary well in advance to evaluate the ability of the transport system to meet the raising transport demand to decrease the city network load and reduce the influence on the environment. The index of the network element adaptability can exist as such an evaluation. This article contains general results and conclusions of the investigation, had been carried out on the section of the Tyumen city highway to reveal and predict the transport demand to evaluate the adaptability of the highway elements to meet the demand outlook.
\end{abstract}

\section{Introduction}

The characteristic feature of nowadays is the increase of life rate. Meanwhile the bigger the megalopolis is, the denser people, transport and information streams are and the bigger the necessity in increasing its velocity is, the more difficulties they experience when moving and the bigger, correspondingly, the time in journey and the possibility of mistakes at their interaction are.

This is natural. That is why the paradigm realization of the "sustainable city" presupposes, first of all, improvement of the methods to control information, transport and pedestrian streams to provide the very possibility of their movement and effective interaction when minimizing their influence on the environment [1-3]. One of the necessary elements of such control is prospecting the load change on the city infrastructure to correct resources planning and prevent the stress situations [4].

\section{Methods of research}

\subsection{Transport demand determination}

In the field of transport streams control there is the notion of transport demand, which is defined as meeting the needs of people in movement. It is caused by the space division of different requirements $[5,6]$. Correspondingly, the existing transport infrastructure and its possibility is named as transport supply [5]. In the accounting methods of prediction

\footnotetext{
${ }^{a}$ Corresponding author: ertmans@list.ru
} 
the problem of determining the future movement intensity is known as well as correspondingly the expenditures to overcome the network elements under the known parameters of transport infrastructure.

Transport demand is characterized by the time and space irregularities. The irregularity of transport demand is influenced by the seasonal factors, changing of the objects of absorption and formation of transport and people steams, schemes and methods to organize their movement and etc. different elements of the transport network have different level of carrying capacity under the influence of one and the same factors. Thus, the elements of transport network possess the adaptability properties to the variable factors of the environment [7].

Adaptability in this context is the property of the transport network elements to keep the values of their characteristic indexes (carrying capacity) on the nominal (optimal, acceptable) level when changing the influencing environmental factors (transport demand) from their standard meanings.

The notion of demand, supply and adaptability is topical for any material and people streams and transport networks. We will stop at the task of determining the adaptability of the city road network to the predicted increase of transport demand, irregular by its nature.

\subsection{The matrix of transport correspondences}

One of the methods to determine the value of the future transport demand is the superposition on the existing or projected transport network of transport correspondences, which are realized by the different ways of journey. Forming the matrix of correspondences is the central and the most complex task, from the mathematical point of view, in all investigations, connected with the essential structural or parametrical changes of transport streams of the city network.

The method of decomposition was used as the method to evaluate the matrix of transport streams correspondences, which is sensitive to the changes of the initial correspondences matrix, of low and top limits being evaluated and artificial variables, which gives the possibility to use it for evaluation of different scenarios of network development and hypotheses of the stream intensity change.

In the method of decomposition the division on the matrixes of correspondences of the smaller order is used so, that the distribution of the correspondences of each of these matrixes is described by the principle "everything or nothing". The given matrixes, used as the evaluation of each of the newly formed correspondences matrixes and describing the belonging of the correspondences to the graph arcs, are binary. This simplifies the preparation of data, their control and visualization. Compensation of the work content increase at increase of the number of the correspondences matrixes being evaluated is the reduce of dimension of each of them.

With the help of the method to restore the matrixes of correspondences it is possible to evaluate the network functioning on the basis of only one kind of the initial data measurements of the stream intensity. In the described investigations the empiric data were used, which were accumulated as the result of movement intensity research on the units (crossroads) and stages of the city road network during the number of years.

The initial data to evaluate the correspondences matrix were presented in the form of oriented graph with the movement intensity values. The description of the network is used at which the correspondences, realized in different ways, are divided into the set of separate matrixes. 
The method set allows to evaluate and predict the influence of different cityconstruction decisions on the size of transport demand under the conditions of heavy traffic in the city.

\section{Empiric research}

\subsection{The section for research}

To analyze the adaptability of the road network elements to the changes of transport demand under the influence of time and city construction decisions factors in the city of Tyumen the section of the highway Staryi Tobolskyi tract was used as an example.

For nearly small period of time on the section of Staryi Tobolskyi tract several decisions of the city construction value were realized, and a number of large objects, attracting transport, cargo and passengers, and pedestrian streams were put into operation (Figure 1):

- "UMMC-Steel";

- JSC Antipinsky Refinery;

- Logistics stocks "VELES"

- Out of town cottage settlements;

- Supermarket "Lenta".

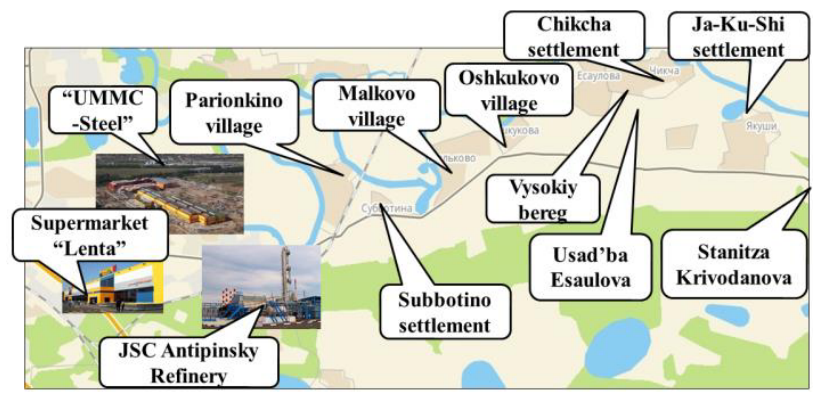

Fig. 1 Summarizing scheme of the section of Staryi Tobolskyi tract.

The section of Staryi Tobolskyi tract at the moment of the investigations beginning (2010 year) had only one possible exit to the city through the intersection of the streets Staryi Tobolskyi, Yalutorovskyi tracts, Respubliki street.

Thus, any change of the range of city and suburban traffic of the streets Staryi Tobolskyi, Yalutorovskyi tract found its reflection in the changes of the traffic intensity at this intersection, it can be with negligible admissions considered that transport demand for the movement along Staryi Tobolskyi tract and out of it was equal to the intensity of forward and backward directions on the pointed out intersection.

Thus, the collection of the transport streams intensity data was being held since 2010 till 2014 just at this very section of the network.

The method of making observations to determine the actual hour intensity of traffic is described, in particular, in the work $[8,9]$.

\subsection{The transport demand exploring}

Maximum average-day values of transport demand, reached at the process of observation, are presented as cartograms for 2010 and 14 years on Figure 2. 

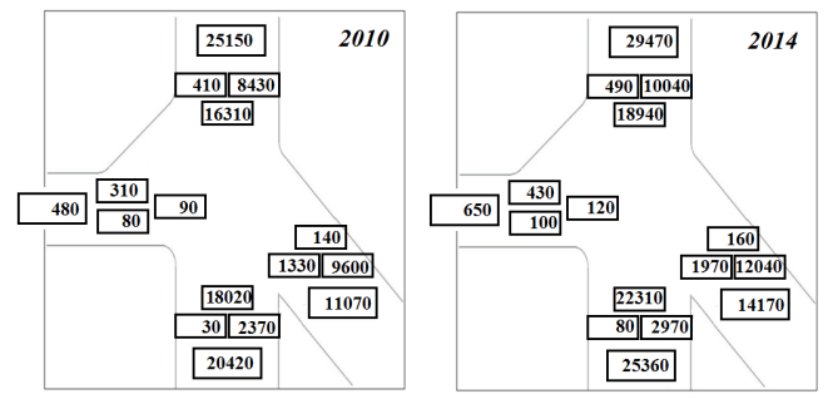

Fig. 2. Cartogram of the maximum average-day values of transport demand on the intersection, reached in 2010, 2012 and 2014 years.

According to the actual values of the traffic intensity and composition, the intersection simulation model was created. It is presented on Figure 3.

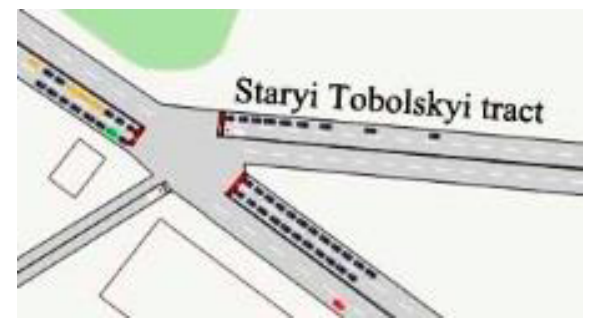

Fig. 3. Intersection simulation model (according to the data of 2012).

\subsection{The correspondences matrixes of transport streams}

Together with making the investigations of the traffic intensity on Staryi Tobolskyi tract, to determine the characteristics of the population mobility, the main purposes of movement were set as well as main points of absorption and regeneration of transport streams (the socalled base sections).

Actual values of average-day, generating and absorbing abilities of the main points were determined. The values of the transport streams correspondences obtained were put over the transport network, being realized by different ways of destination to (and from) the base sections. Thus, each of them was considered as a separate correspondence.

The data obtained allowed to get a set of binary correspondences matrixes of transport streams along the whole extent of the road section under consideration.

To get the general matrixes of transport correspondences all routes of traffic on the section of the highway Staryi Tobolskyi tract were presented in the view of the orientated graph $[5,6]$ (Figures 4-8).

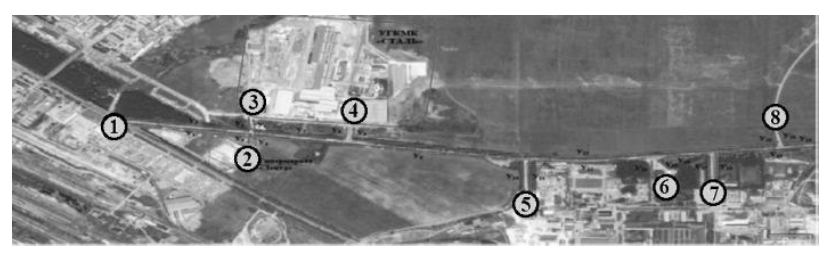

Fig. 4. Section of the road Staryi Tobolskyi tract 1-3 km. 


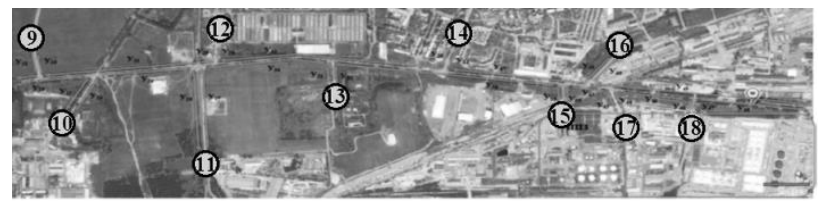

Fig. 5. Section of the road Staryi Tobolskyi tract 3-6 km.

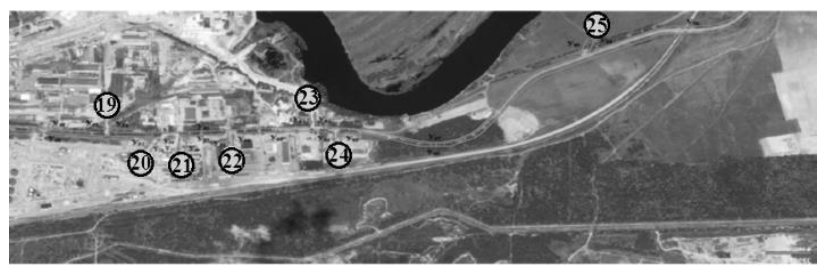

Fig. 6. Section of the road Staryi Tobolskyi tract $6-10 \mathrm{~km}$.

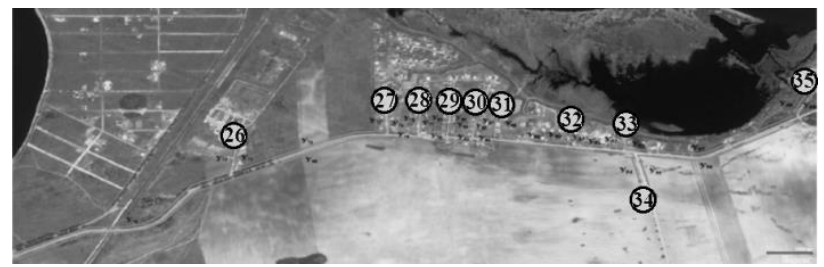

Fig. 7. Section of the road Staryi Tobolskyi tract 10-13 km.

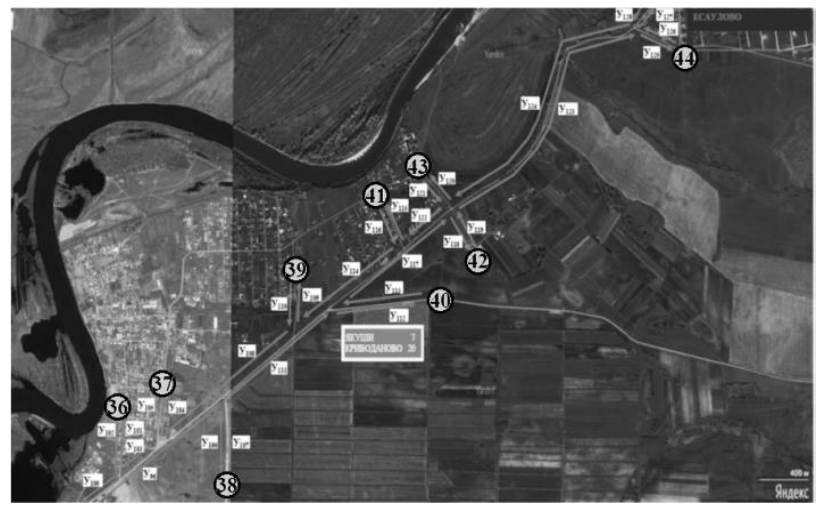

Fig. 8. Section of the road Staryi Tobolskyi tract 13-20 km.

Thus, on Figures 4-8 the section of the highway of Staryi Tobolskyi tract is presented by the oriented graph, including 44 corresponding tops and 128 arcs.

On the basis of the data obtained transport correspondences matrix was determined. Unfortunately, because of a big volume of the correspondences matrix obtained, it cannot be presented in this very article.

\subsection{The predicted estimates}

For each separate correspondence, connected with a base section, hypotheses of changing the average-day and annual density of traffic were formulated on the basis of the known time trends of occupation the territories, dedicated for the construction (for cottage settlements), productive plans of enterprises development (for "JSC Antipinsky Refinery" 
and "UMMC-Steel"), growth of birthrate and auto mobilizing the population (for Antipino settlement, Oshkukovo village, Esaulovo settlement, Malkovo village, Subbotino settlement, Chikcha settlement, etc.)

The predicted estimates of increasing the population mobility obtained allowed to determine the hypothetic value of transport demand for the movement along Staryi Tobolskyi tract for the middle and long-term perspective and model the scenarios of road traffic movement condition in different elements of the road network section under consideration. On Figure 9 an example of the transport demand model is presented in 2018 under the 2012 data of the carrying capacity of the key intersection.

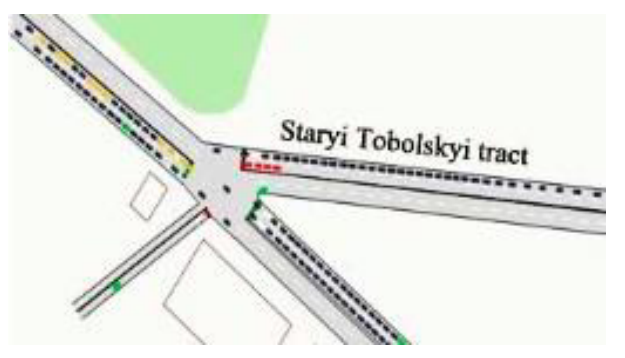

Fig. 9. Model of transport demand at the scenario of development for 2018.

As a result of a comparative analysis of the predictive estimates of increasing transport demand, obtained when using the correspondences matrix, with the characteristics of traffic movement in the dynamics being observed at the intersection under consideration, the values of statistic characteristics were obtained proving the hypotheses got.

\subsection{The estimates of adaptability}

The estimates of adaptability of different elements of the highway section under consideration were obtained at the scenario of increasing transport demand for 2018 (Figure 10).

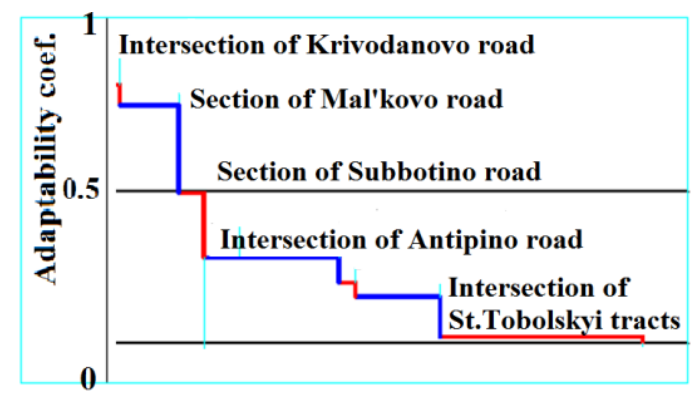

Fig. 10. The estimates of adaptability of different elements of the Staryi Tobolskyi tract road.

At increasing transport demand to the values of 2018 adaptability of the majority of highway section elements is reduced to the values, close to 0 . Thus, without the improvement of the road network, realization of the scenario to increase transport demand would be impossible. City construction plans to change the schemes of road traffic organization at the section of Staryi Tobolskyi tract were realized in 2014.

Transport model of the section with taking into account the changes made by the scenario of the development till 2018 allowed to determine that the values 
of the adaptability coefficients of the intersections increased in comparison with the estimates, obtained without changes, to the average values.

However, implementation in the transport model the scenario of a long-term transport demand development till 2030 again gives reduction of coefficient values of adaptability to critical values.

\section{Discussion}

Thus, it is necessary to make control decisions beforehand to increase a carrying capacity of the road network section elements on Staryi Tobolskyi tract and their realization to 2025 . The ways of raising the carrying capacity at present are the subject of discussion.

\section{Conclusions}

The results obtained in the course of making investigations, allowed to make the following conclusions.

1. Getting the predicted estimates on changing transport demand and parameters of road traffic under the influence of putting into operation large city construction objects is possible far before the transport collapse occurrence at separate sections and is necessary under the conditions of paradigm realization of the "sustainable city" [2, 4].

2. Determination of the transport correspondences matrix, and the means of simulation modelling allow to get the whole picture of such a change $[5,6,10]$, that gives a possibility to plan technical and organization decisions beforehand to level this influence [9].

3. As an estimate of possibilities of road network different elements to meet the transport demand with taking into account its changeable character, and for the perspective, it is possible and reasonable to use the coefficient of adaptability, having the necessary properties of information value, visualization, comparability.

\section{References}

1. G. Schliwa, R. Armitage, S. Aziz, J. Evans and J. Rhoades, RTBM, 15, 50-57 (2015)

2. M. Kiran, EP, 58, 347-357 (2013)

3. I. Anisimov, A. Ivanov, E. Chikishev, D. Chainikov and L. Reznik, EMP in 21 st century, 685-696 (2014)

4. A.S. Santos and S.K. Ribeiro, CSTP, 3 (4), 415-420 (2015)

5. D. Lohse, Transport supply and demand modeling for private and commercial transport - a model-theoretically survey TU (Dresden, 2004)

6. A. Comi1, P. Delle, F. Filippi and A. Nuzzolo, ET, 51, 7 (2012)

7. J. Ertman, S. Ertman, I. Anisimov, D. Chainikov and Y. Chikishev, RJPBCS, 6 (1), 1761-1770 (2015).

8. Yu.A. Ertman and S.A. Ertman, Science Prospects, 8 (59), 48-51 (2014)

9. Yu.A. Ertman and S.A. Ertman, Science and Business: Ways of Development, 8 (38), 713 (2014)

10. J. Muñuzuri, J.H.R. van Duin and A. Escudero, Procedia - Social and Behavioral Sciences, 2 (3), 6165-6176 (2010) 